\title{
Relationship between Recruitment of the Antarctic Krill and the Degree of Ice Cover near the South Shetland Islands
}

\author{
So Kawaguchi and Mikio Satake \\ Central Research Laboratory, Nippon Suisan Kaisha Ltd., Kitano, Hachioji, Tokyo 192, Japan \\ (Received February 10, 1993)
}

Key words: antarctic krill Euphausia superba, sea ice, recruitment, body length

In the Antarctic Ocean, sea ice is one of the most important factors which governs the marine ecosystem. ${ }^{1}$ The area around the South Shetland Islands is one of the best fishing grounds for the Antarctic krill Euphausia superba. ${ }^{2)}$ Using log book data from the krill trawlers of Nippon Suisan Kaisha Ltd., and data on the degree of sea ice cover in austral winter, we tried to describe the relationship between the degree of sea ice cover in austral winter and the recruitment of small krills near the South Shetland Islands. The data on the degree of sea ice over 12 years from 1979 to 1992 used in this study was obtained from the NAVY - NOAA Joint Ice Centre, the Naval Polar Oceanography Centre, Suitland. Using the log book data of commercial trawlers, it is possible to discuss on the basis of a massive amount of data accumulated by intense operations, which is useful for predicting of natural environment.

As juvenile and immature krills are distributed around the coastal zone, ${ }^{3)}$ we examined recruitment from the data on the coastal zone only (Fig. 1). The degree of sea ice cover was expressed as the sea ice extent on the $60^{\circ} \mathrm{W}$ line in austral winter (Fig. 1). In the log book data, average body length (from the anterior edge of the eye to the posterior tip of the telson) of the catch per haul is described as $M$ $(<38 \mathrm{~mm}), \mathrm{L}(38 \mathrm{~mm}-44 \mathrm{~mm})$, or LL $(44 \mathrm{~mm}<)$. Based on Sigel, ${ }^{4)}$ the mean body length of ages $1+, 2+$, and $3+$ are $30.0 \mathrm{~mm}, 39.4 \mathrm{~mm}$, and $44.5 \mathrm{~mm}$, respectively. Therefore, the ages of $1+, 2+$, and older than $3+$ will be mainly involved in $\mathrm{M}, \mathrm{L}$, and $\mathrm{LL}$ in our definition, respectively. By setting size numbers $M=-1, L=0$, and $L L=1$, the size index of each fishing season was defined by the following calculation.

Size index $=$

$$
\frac{\sum \text { (size number of each haul in the coastal zone) }}{\text { net haul for a season in the coastal zone }}
$$

When the value of the size index is low, it shows that the ratio of juveniles or small krills is high. In Fig. 2, the calculated size index and the extent of the sea ice on the $60^{\circ} \mathrm{W}$ line in austral winter are shown. In $80 / 81,81 / 82$, $87 / 88,88 / 89$, and 91/92 fishing seasons (December through April), the size index was relatively low. This means that abundance of small krill was relatively high. These low index fishing seasons always followed after a season of heavy sea ice cover. However, when the sea ice did not develop, the size index was high. This result suggests that heavy ice cover in austral winter leads to a relatively high abundance of small krill in the population.
We can imagine that in some way, the heavy sea ice cover might help the survival of larva during austral winter, and therefore that the relative abundance of age $1+$ will increase in the fishing season. Eventually, it may be reflected as a low size index of the catch.

Daly $^{5)}$ indicated that young krills were associated primarily with first year ice which provided a variety of habitats for microbial population, and the undersurface of the pack ice may be nursery areas. Krill also selectively seek out the deeper lying recesses in the ice to hide from large predators. ${ }^{6)}$ Moreover, the lack of lipid reserves suggest that larvae may need to feed on ice algae in winter. Thus, larvae will have a greater dependence on ice algae in the winter than do adults. ${ }^{7)}$ In our data, large recruitment

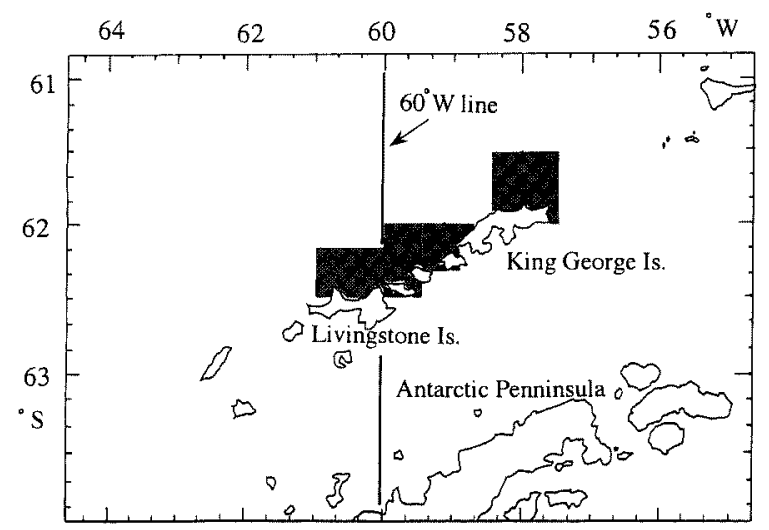

Fig. 1. The data source area (hatched area) used for the calculation of the size index

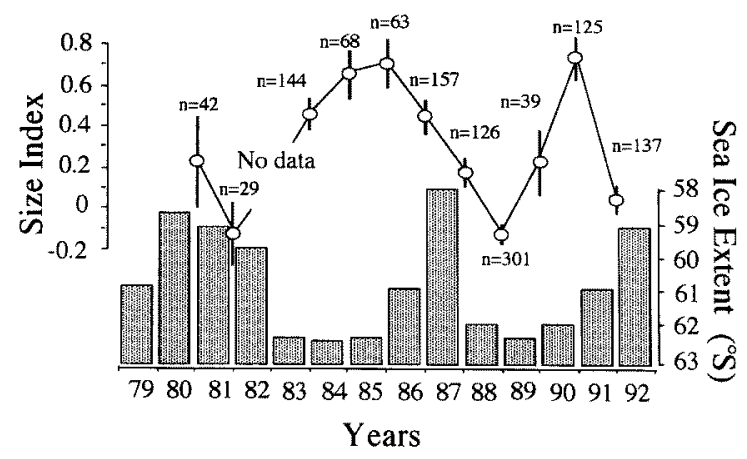

Fig. 2. Relationship between the size index of krill (open circle $\pm 95 \%$ confidence limit) and the degree of sea ice cover (hatched column). 
after a strong sea ice extent was suggested. This phenomenon could be explained by the high rate of larval survival, which was supported by a sufficient food supply and predator avoidance effect due to the strong sea ice extent.

In this paper, the environmental factor on which we focused was only the degree of sea ice cover. Although many other environmental factors must be considered in order to discuss Antarctic krill ecology, our result gives us an interesting implication on the relationship between the degree of sea ice cover and the recruitment of the Antarctic krill.

The authors thank Mr. T. Ichii of the National Research Institute of Far Seas Fisheries for his helpful advice.

\section{References}

1) D. Sahrhage: in "Antarctic Ocean and Resources Variability" (ed by D. Sahrhage), Springer-Verlag, Berlin-Heidelberg, 1988, "pp. $33-40$.

2) T. Ichii: Proc. NIPR Symp, Polar Biol., 3, $36-56$ (1990).

3) V. Sigel, B. Bergstrom, J. O. Stromberg, and P. H. Schalk: Polar Biol., 10, 549-557 (1990).

4) V. Sigel: Mar. Biol., 96, 483-495 (1987).

5) K. L. Daly: Limnol. Oceanogr., 35, 1564-1576 (1990).

6) H. P. Marchall: Polar Biol., 9, 129-135 (1988).

7) L. B. Quetin and R. M. Ross: Amer. Zool, 31, 49-63 (1991) 